\title{
SCYLLA AND CHARYBDIS: THE PURIST'S DILEMMA
}

\section{Leon Culbertson (ORCID ID: 0000-0002-9101-5851)}

This paper explores the view that, on Mumford's account of the purist, to the degree that the purist adopts an aesthetic perspective, he or she doesn't watch the sport in question, and to the degree that he or she does watch the sport, there is a loss of aesthetic appreciation. The idea that spectators oscillate between partisanship and purism means that the purist is unable to avoid either the Scylla of not actually watching the sport, or the Charybdis of loss of aesthetic appreciation at any given point. Ultimately there seems to be both a sport-shaped hole and an aestheticshaped hole in Mumford's account of the purist.

It is argued that oscillation is incapable of dealing with the problem precisely because it is disjunctive in nature and entails the spectator either watching sport from an aesthetic perspective or from a partisan perspective at any given time. An alternative conception of the aesthetic is considered that offers one way of dissolving the purist's dilemma.

KEYWORDS aesthetics; partisan and purist; sport spectatorship.

\section{Introduction}

In an excellent discussion of the relationship between emotions and aesthetics in sport spectatorship, Stephen Mumford (2012c) began the task of exploring the complexities of that relationship if one takes, as one's starting point, the view of sport spectatorship he develops in detail in Watching Sport: Aesthetics, Ethics and Emotion (2012a) and augments in Mumford (2012b). His primary concern is with the question of whether there is 'an inevitable trade-off' when watching sport from an aesthetic perspective on the one hand, or from a competitive perspective on the other. ${ }^{1} \mathrm{He}$ concludes that the matter is complex, and that while there are many cases where there is such a trade-off, there are also some important exceptions, although they are only 'from a limited range mainly in the area of the beautiful victory' (Mumford, 2012c: 278). He argues that although the purist 'may miss out on the intense aesthetic experiences associated with engaged emotions', he or she 'has far greater range and variety of aesthetic experience as open possibilities for his or her enjoyment' (Mumford, 2012c: 279).

This paper explores a similar concern to that discussed in Mumford (2012c), but one that is broader in focus, and, I think, has important implications for what we make of Mumford's theory of sport spectatorship as a whole. The paper will explore the view that, on Mumford's (2012a; 2012b; 2012c; 2013; forthcoming) account of the purist, to the degree that the purist adopts an aesthetic perspective, he or she doesn't watch the sport in question (at least in cases of purposive sports), and to the degree that he or she does watch the sport, there is a loss of aesthetic appreciation. The idea that spectators oscillate between partisanship and purism, and that someone's spectatorship can be placed on a spectrum (perhaps even as a result of 
quantification), means that the purist is unable to avoid either the Scylla of not actually watching the sport, or the Charybdis of loss of aesthetic appreciation at any given point. Ultimately there seems to be both a sport-shaped hole and an aestheticshaped hole in Mumford's account of the purist.

The paper will begin by outlining Mumford's account of the aesthetic perspective of the purist by identifying six features of that account that are relevant to the concerns discussed here (\$2). It will be argued (\$3) that Mumford's conception of the aesthetic is idiosyncratic (much of what he takes to be aesthetic doesn't seem to warrant such a description), and, as a consequence, most of the concerns of the purist don't seem to be what we might properly call 'aesthetic' at all. This is one way in which Mumford's account appears to suffer from an aesthetic-shaped hole. Consideration will be given to what it amounts to if one regards the aesthetic perspective as something that, if adopted, must be to the exclusion of the partisan/competitive perspective. This will be considered in two contexts, namely, in relation to the partisan/competitive perspective (\$3), and in relation to the purist perspective (§4). It will be argued that conceiving of the aesthetic perspective in that way means that the partisan perspective leads to a loss of aesthetic appreciation (a second way in which Mumford's account suffers from an aesthetic-shaped hole). It will also be argued that if this disjunctive conception of the aesthetic and competitive ways of watching sport is adopted, such a view leads us to fall into the problem of not actually watching the sport, which constitutes a sport-shaped hole in Mumford's position. Mumford's account of the purist, therefore, faces the dilemma of how to avoid the Scylla of an aesthetic-shaped hole and the Charybdis of a sportshaped hole. Someone might think that Mumford's oscillation theory of spectatorship resolves the problem outlined here, so that will be considered. It will be argued that oscillation is incapable of dealing with the problem precisely because it is disjunctive in nature and entails the spectator either watching sport from an aesthetic perspective or from a partisan perspective at any given time. An alternative conception of the aesthetic will be considered (in $\S 5$ ) that offers one way of dissolving the purist's dilemma.

\section{The aesthetic perspective of the purist}

There are six features of Mumford's conception of the aesthetic perspective of the purist to which I want to draw attention here for the purpose of providing a structure and clarity to the argument made in the paper. Those features are as follows:

a. Mumford regards certain things as constituting examples of the aesthetic that one might not normally categorise in such a way. At various points enjoyment, appreciation of tactics, watching skilful players, seeing both sides play well and to their full potential, seeing an eventful, rather than an uneventful, game, excitement, time limitation of play, entertainment, doing something well, an event being a spectacle, and sport being popular to watch, are all, in one way or another, given as examples of features of the aesthetic way of watching sport, or of aesthetic features of sport. I stress 
'aesthetic' here because Mumford does not suitably distinguish between the aesthetic and the purist ways of watching sport. He says that the purist's interest is 'mainly in the aesthetic experiences' sport can provide (Mumford, 2012a: 19, emphasis added), and that he advocates 'a more aesthetic mode of sports watching' (Mumford, 2012a: 10, emphasis added), but 'mainly' and 'more' do not function as qualifiers in the sense one might think. There is no meaningful distinction between a purist way of watching sport and an aesthetic mode of perception in watching sport identified or in operation in Mumford's account. So it isn't the case that the examples given above (enjoyment, appreciation of tactics, watching skilful players etc.) constitute features of the purist way of watching sport that aren't features of the aesthetic way of watching sport, or aesthetic features of sport. ${ }^{2}$

b. Mumford thinks that the drama in sport introduces an aesthetic dimension that renders time limitation of play aesthetic in nature, or of direct relevance to the aesthetic in sport. The idea here is that drama is aesthetic in nature and time limitation of play increases the potential for drama in sport, so time limitation increases the potential for the aesthetic in sport.

c. Mumford employs a broad conception of the aesthetic in one sense (that referred to in (a) above), yet a narrow conception of the aesthetic in another sense because he only considers positive aesthetic value. Mumford often employs the term 'beauty' and makes it clear that in doing so he means 'positive aesthetic value' (2012a: 41), and his focus in discussing art and the aesthetic remains on positive aesthetic value and does not extend to the wider sense in which we use the term 'aesthetic', which includes 'the dainty and the dumpy' (Austin, 1979: 183. Also see McFee, 2015: $134 \mathrm{n} 18$, and 213, and Best's, 1978: 99-100 distinction between the conceptual and evaluative uses of 'aesthetic'). So while Mumford (2012a: 58) wants to follow Eaton (2004: 73) in (in one sense) having a broader conception of the aesthetic, his focus on positive aesthetic value, means that (in a different sense) he has a narrow conception of the aesthetic.

d. Mumford treats, what he calls, the 'aesthetic mode of perception' as entirely distinct from the competitive way of watching sport. He (2012a: 57) claims that:

[t]he purist is someone who has this aesthetic mode switched on most of the time, looking at the sporting contest aesthetically. The partisan rarely has it switched on. But there are many possibilities between the fanatic partisan and the out-and-out purist. Many who watch sport will have some combination of partisan and purist tendencies and will switch their aesthetic mode on and off as the occasion takes them.

The aesthetic and competitive ways of watching sport are what I have called elsewhere (reference omitted for purposes of review) the two (and only two) 'foci' of sports spectatorship on Mumford's account, and the fact that the two foci are distinct from each other required Mumford to give an account of how a spectator could move between the two. 
e. Mumford thinks spectators oscillate between the partisan and purist ways of watching sport. The account Mumford gives (2012b) of how spectators can move between the distinct foci of an aesthetic mode of perception in watching sport in the purist manner and the competitive perception of the partisan consists in the claim that spectators oscillate between the two (see (reference omitted for purposes of review) detailed discussion and criticism of the oscillation theory). ${ }^{3}$

f. Mumford advocates a form of adverbial theory of perception that he applies to sport spectatorship. Mumford is concerned to offer an account that defends the notion of a distinct 'aesthetic mode of perception' (2012a: 5767), and a function of the adverbial view of perception, according to which we see, for example, 'bluely' when looking at something blue, is that it supports the idea of distinct modes of perception, but not in the usual sense in which we talk of modes of perception (seeing, hearing, tasting, touching and smelling), ${ }^{4}$ rather in the sense of seeing in particular ways (bluely, redly, squarely, aesthetically). The notion of the purist way of watching sport is, therefore, something that can be understood as a consequence of the application of an adverbial theory of perception, with an emphasis on the notion of a distinct aesthetic mode of perception, to sport spectatorship.

These are not all entirely distinct features in that some of them overlap to a significant degree, but differentiating between them will help in what follows.

\section{Scylla: the competitive perspective}

In this section it will be argued that Mumford's account of the purist way of watching sport suffers from an aesthetic-shaped hole in two ways. First, Mumford's conception of the aesthetic is such that it is, in one sense, broader than one might normally expect, and ultimately too broad, yet in another sense narrower than one very common use of the term 'aesthetic'. His conception of the aesthetic seems, therefore, in this latter sense, to be too narrow. Second, Mumford's insistence on a sharp, exclusive distinction between the partisan and purist ways of watching sport, and tendency to conflate an aesthetic mode of perception with a purist way of watching sport, leads to an account on which watching sport in the competitive way excludes aesthetic appreciation, at least intermittently. I will address those two difficulties in turn.

\section{The purist and the aesthetic}

Mumford (2012a: 10) describes the purist as follows:

The purist is a fan of sport, and may love deeply the sport concerned, but has no allegiance to any particular team. They may attend games and enjoy them despite having no preference for either team to win. I contend that Dixon (2001) gets the purist wrong in this respect, ${ }^{5}$ identifying them as someone whose allegiance shifts according to which currently is the best team. That just makes them a different (fickle) kind of partisan. But instead, the purist 
enjoys the game in a different way from a partisan. They may enjoy working out the tactics of the two teams and seeing how the play develops, how the tactics are adapted to fit new circumstances, and how the game has key moments of drama. They may also enjoy seeing individual skilful players, perhaps competing against each other, and will want both sides to play well, to their full potential. The partisan, in contrast may be very happy if the opposition team underperforms. An eventful game will be more pleasing than an uneventful one to a purist, who will certainly want to see a "good" game. But what makes a good game is not necessarily dependent on the result, given that they have little preference for either of the teams. The purist, I will argue, has not been correctly understood, and ... I will be defending the purist against various claims made by those who think that partisanship is the right way to watch sport. In response, I will be advocating a more aesthetic mode of watching sport.

There are a number of things to which attention should be drawn here. It is important to remember that Mumford (2012 a: 10) ends the passage by stressing that he 'will be advocating a more aesthetic mode of watching sport' [emphasis added]. Given that, it is interesting to note the features of a purist way of watching sport that he identifies in this passage.

i. He stresses that the purist has no allegiance. A lack of allegiance may contrast the purist with the partisan, but there is nothing necessarily aesthetic in, or that follows from, a lack of allegiance. The lack of a distinction between the aesthetic way of watching sport and the purist way of watching sport means that things that distinguish the purist way of watching sport, such as a lack of allegiance, seem to be, on Mumford's account, features of an aesthetic way of watching sport, but there is nothing necessarily aesthetic about them (this is true of most of the examples given in $\S 2$ point a).

ii. Mumford also places emphasis on enjoyment, but, again, while aesthetic appreciation can be pleasurable, there is nothing about enjoyment per se that entails the aesthetic.

iii. The passage cites an appreciation of tactics as a central element of the purist way of watching sport, but not only is there nothing necessarily aesthetic to the appreciation of tactics, one might reasonably think that competition is a necessary consideration in the appreciation of tactics precisely because a central criterion for such appreciation would be whether the tactics in question were successful, and success in the case of tactics is gaining a competitive advantage. In Mumford's (2012 a: 21) discussion of the appreciation of tactics as a feature of the purist way of watching sport, there appears to be a conflation of the intellectual and the aesthetic, and there is a danger that the purist and partisan collapse into each other because tactics cannot be separated from their aim, which, as already noted, is to gain a competitive advantage. The 'intellectual delight' that accompanies tactical discoveries on the part of the spectator may be similar to that 'found in learning and acquiring a new understanding that one previously lacked' (2012a: 21), and there 
may be 'pleasure in the satisfaction of wonder, curiosity and desire to understand' (2012a: 21), but that does not make the intellectual aesthetic, nor does it identify an essentially aesthetic dimension to the appreciation of tactics.

iv. Appreciation of the drama in sport is suggested as a feature of the purist way of watching sport. Someone might think, indeed Mumford does, that this is a clear example of aesthetic appreciation of sport, but that is to fail to accept that the use of the term 'drama' in this case is figurative and does not entail an aesthetic dimension as it does when used in the conventional way, such as when referring to watching a play in the theatre.

v. Mumford notes that the purist enjoys watching skilful players, but, again, there is nothing necessarily aesthetic about watching skilful play, and the distinction between an aesthetic way of watching sport and a competitive way of watching sport seems all the more unclear given that Mumford (2012a: 10) acknowledges that 'perhaps' the appreciation of skilful play may be in the context of players 'competing against each other'.

vi. The purist wants both sides to play well, and to their full potential. Again, there is nothing necessarily aesthetic about both sides playing well and to their full potential.

vii. The purist would rather see an eventful, rather than uneventful, game - a good game, where what is regarded as 'good' is not necessarily dependent on the result. However, a game could be good, in a sense that isn't dependent on the result, by being a game in which both sides played to their full potential, but, as already noted, there is nothing necessarily aesthetic about that, so there is nothing necessarily aesthetic about a good game.

The theme to which I wish to draw attention here is Mumford's habit of regarding the purist way of watching sport as principally aesthetic, while then giving a series of examples of features of the purist way of watching sport that aren't necessarily aesthetic in nature.

Other examples can be found. Mumford (2012 a: 19) clearly thinks that excitement is an aesthetic experience, as he claims that ' $[t]$ he purist appreciates excitement and other aesthetic experiences that sport provides', but there is nothing aesthetic about excitement. The fact that one might experience excitement on viewing certain works of art does not mean that excitement is an essential feature of the aesthetic, and $a$ fortiori, it does not mean that wherever there is excitement, there is an aesthetic experience. A child may experience excitement on Christmas morning, but that does not mean that he or she is having an aesthetic experience.

Also, as I have argued elsewhere (reference omitted for purposes of review), there is something curious about Mumford's (2012a: 23-4) consideration of, and rejection of, the suggestion that time limitation within sport could be an aesthetic flaw. By this I do not mean to suggest that Mumford is wrong to reject the suggestion that time limitation is an aesthetic flaw, but rather to point out that time is not an aesthetic 
category, so time limitation dictates the period during which there are aesthetic possibilities within a game or sport, and in that sense constitutes part of the conditions for the possibility of play of any kind (whether beautiful, ugly, or aesthetically neutral), but that does not render time an aesthetic category. What is curious, therefore, is not Mumford's rejection of the idea that time limitation within sport is an aesthetic flaw, but his suggestion that time limitation enhances the aesthetic qualities of sport. Time limitation neither enhances nor detracts from the aesthetic qualities of sport, it simply places restrictions on the period during which play of any kind is possible. In music the time available for performance has an influence on aesthetic possibilities. For example, Wagner had many options when composing Der Ring des Nibelungen, which, in total, is fifteen-and-a-quarter hours long and performed over three days and a preliminary evening. Many of those options were not available to those composing music for recording during the early period of recorded music because the technology was such that only around twoand-a-half minutes of music could be recorded on one side of the record. ${ }^{6}$

Mumford (2012a: 59) regards Sibley $(1959 ; 2001)$ as an example of someone who, 'defends the idea that there is a clear distinction to be made between aesthetic and non-aesthetic properties. We can distinguish the sentimentality of a play, for instance, from one of its non-aesthetic properties, such as being two hours long, or the arrangement of colours in a painting from the weight of the painting.' Sibley (2001: 1) does seek a clear distinction on the basis of whether the application of a term or expression 'requires the exercise of taste, perceptiveness or sensitivity, of aesthetic discrimination or appreciation' [emphasis added]. However, he does not argue for the idea that there are two categories, that of aesthetic concepts, and that of non-aesthetic concepts, and all concepts belong to one or the other of those two categories, and only to one of the two categories. On the contrary, he (Sibley, 2001: $1 \mathrm{n} .1$ ) rightly acknowledges that it is not the concept, but its use, that determines whether it should be thought of as an aesthetic concept when used in a given way (and, one would wish to add, in a given context, as the context is part of any account of the way a concept is used). He stresses (2001: 2) that the examples that he gives 'are expressions which, appearing in critical contexts, most usually, if not invariably, have an aesthetic use; outside critical discourse the majority of them more frequently have some other use unconnected with taste. But many expressions do double duty even in everyday discourse, sometimes being used as aesthetic expressions and sometimes not.' In addition, he (2001: 2) distinguishes a category of terms that 'function only or predominantly as aesthetic terms' (such as 'graceful', 'dainty' and 'handsome'), and is also clear that there are 'many words which are seldom used as aesthetic terms at all' (such as 'red', 'square', 'intelligent', 'docile' and 'faithful').

There are a number of things to stress from this. First, Mumford talks of aesthetic 'properties', whereas Sibley is considering terms and expressions, extending to concepts. This is important because Sibley's approach rightly preserves sensitivity to the fact that terms and expressions can be used in different ways and in different contexts. ${ }^{7}$ That is quite different from the idea that things have properties and those properties can be classified in various ways, and in this case the relevant 
classification is whether the properties are aesthetic properties or not. That is not to claim that we don't distinguish properties, of course we do, but rather to emphasise that when we do so, we employ terms and expressions, the majority of which have both aesthetic and non-aesthetic uses. So when we appropriately ascribe an aesthetic property to something, we do so by appropriately employing a term or expression in an aesthetic sense (the context of employment determining appropriateness), but that does not mean that every time we appropriately employ that term or expression in any way, we have identified an aesthetic property.

So it is important to recognise here that the issue is not necessarily the same in relation to the two cases that Mumford describes. For example, it's hard to think of any case where time per se could be an aesthetic property, yet, although the weight of the painting is not an aesthetic property of the painting, one might feel that there are aesthetic differences between a small solid marble sculpture and a small hollow marble sculpture, and that under such circumstances the weight of the sculpture might constitute an aesthetic consideration in one sense identified by Sibley (2001: 2), namely, that in which terms and expressions 'do doubt duty'. Equally, someone might feel that Samuel Beckett's play Not I, which was written to be delivered as quickly as possible, loses an aesthetic quality if it is delivered too slowly. Similarly, playing a piece of music too fast or too slow can have a detrimental impact on the aesthetic qualities of the piece. In both cases, however, it is not time that is the aesthetic property, but tempo. ${ }^{8}$

We might normally regard aesthetic appreciation in sport as something principally, although not necessarily exclusively, focused on particular passages of play, rather than on the event as a whole (in contrast, one can appreciate particular passages in music, but generally we tend to appreciate the whole piece). Time limitation does not, in itself, therefore, place restrictions on many of the activities that we might regard as aesthetically pleasing in sport in that most of those activities can be executed in much less time than is permitted in sport, so any restrictions occur as a result of the point in the game at which a player wishes to do something.

Mumford seems to think that time limitation leads to drama, which is an aesthetic matter (see Mumford, 2012 a: 24). There doesn't seem to be anything contentious about the claim that time limitation can create the possibility of drama as a game nears its conclusion. However, that is not the drama of the theatre, and is not, therefore, an artistic and/or aesthetic matter (see Best, 1978: 117). That being the case, linking time limitation to drama (of the kind relevant to sport) does not link time limitation to the aesthetic. ${ }^{9}$

Mumford (2012 a: 46-7) treats a range of other things as aesthetic where it seems quite clear that we would not normally do so. For example, entertainment, doing something well, an event being a spectacle, a sport being popular to watch, and enjoyment (the golden goal example) all seem to be conflated with being aesthetically pleasing. 
An indication of why Mumford might have such a broad conception of the aesthetic can be found in his claim (Mumford, 2012a: 58) that:

aesthetic quality is no longer ${ }^{10}$ restricted just to beauty .... New works of art, such as Duchamp's Fountain ${ }^{11}$ challenged the narrow conception. As well as beauty, we now use aesthetic concepts such as a work being interesting, dramatic, challenging, moving, evocative and so on (Eaton 2004: 73). Eaton thinks the concept of the aesthetic should be broadened to encompass such additional notions, and I follow her in this.

This would seem to explain Mumford's very broad, someone might even think, rather idiosyncratic, conception of the aesthetic; it is only unusual if one has a very traditional, narrow, conception of the aesthetic as solely concerned with beauty. However, that is not the case. The relevant sense of 'aesthetic' in which a work can be interesting is not just any old way that it might be interesting. Equally, being dramatic in an aesthetic sense is not the same as being dramatic in the sense that two people having a fight in the street is dramatic, or the last minute of a finely balanced cup final is dramatic. Similarly, the idea that a work being challenging is an aesthetic matter is not the idea that it is sufficient to be challenging in any old way, nor is it sufficient for a work to move someone or be evocative for someone per se. Someone might be moved by something that is an ordinary occurrence in their lives because of something else that has happened to them recently, such as bereavement, but we wouldn't say that bereavement heightens our aesthetic sensibilities in such a way that when we are moved by something perfectly commonplace because of our recent bereavement, then we have had an aesthetic experience. ${ }^{12}$

However, there is another reason why that justification for Mumford's broad conception of the aesthetic is problematic. It isn't the concept of the aesthetic that has been broadened by developments in art during the twentieth century, but the concept of art. Eaton (2004: 64) argues that '[t] he class of artistic objects is strictly included in the class of aesthetic objects, but is not identical to the class of aesthetic objects'. In addition, she observes (correctly) that '[I]n the twentieth century, at least in technological societies, "beauty" began to move from the center or at least share it with other qualities, .... "Interesting," "dramatic," "challenging," "evocative," "moving," for example, were more and more often applied to artworks' (Eaton, 2004: 73 emphasis added). However, it does not follow that if the concept of the artistic is entirely contained within the larger category of the aesthetic, and the various terms listed have increasingly been applied to art, that our conception of the aesthetic should be broadened to include just any use of the terms listed. There are two things to see here. First, the fact that to be entitled to draw a conclusion about the aesthetic from an observation about art in this way would require the aesthetic and the artistic to be identical (which, Eaton, rightly, does not want to claim). Second, it is necessary to pay attention to the sense in which the listed terms are used in relation to art because those are specific kinds of use, not just any use. 
Danto (2013: 23ff.) discusses both Duchamp and Warhol in this regard and rightly stresses that while 'Duchamp, as a Dadaist, tried as a matter of Dada principle to forebear producing beautiful art' (2013: 24) the important observation to be made from the example of Duchamp's 'readymades' ${ }^{13}$ is not that it led to a broadening of the notion of the aesthetic (see note 10 for an indication of why such a thing could not be the case), but rather a development in what is regarded as art, which is an entirely different kind of concept from the aesthetic and can be altered by the activities of artists.

Another, related, thing to stress here is that not only is the aesthetic not solely a matter of positive aesthetic value (Austin, 1979: 183; Best, 1978: 99-100; McFee, 2015: $134 \mathrm{n} 18$, and 213; Danto, 2013: 1-52), but that there is no essential connection between art and the aesthetic (see Danto's, 2013: 35ff. discussion of Warhol's Brillo Boxes and the visual irrelevance of art). So there is no extension of the concept of the aesthetic because of the activities of artists such as Duchamp and Warhol.

What the discussion thus far in this section is designed to show is that there is what we might call an 'aesthetic-shaped hole' in Mumford's account in the sense that he regards the purist way of watching sport as being principally an aesthetic way of watching sport, yet so many of the features of the purist way of watching sport that he identifies by way of exemplification are the kinds of things that it just seems strange to regard as aesthetic, and Mumford's appeal to Eaton as a justification for a broader conception of the aesthetic does not seem to address the concern here, as that concern is not over the use of concepts such as something being interesting, dramatic, challenging, moving or evocative in an aesthetic sense, but rather that the examples Mumford gives are not examples of concepts such as those used in an aesthetic sense. However, that is only one way in which we might think of Mumford's account as suffering from an aesthetic-shaped hole. His conception of the aesthetic mode of perception as distinct from a competitive way of watching sport creates an aesthetic-shaped hole in a second sense.

\section{A distinct aesthetic perspective}

Mumford (20012a: 57) argues that 'there is a distinctly aesthetic mode of perception of which we are capable and we deploy when we look at art [although] [w]e can deploy this aesthetic perceptual mode when observing other things as well as art' [emphasis added]. The degree to which an aesthetic mode of perception is distinct, or, what seems more problematic, must be distinct from a competitive or partisan way of watching sport is important to the difficulty outlined here.

If watching sport from an aesthetic perspective and watching it from a competitive perspective are regarded as distinct, and as things that one does only when not doing the other, then concentrating one's attention on the competitive nature of the sport could be thought to lead to a loss of aesthetic appreciation (hence, what might seem a rather puzzling title to this section; one side of the dilemma for Mumford's purist is that being drawn to the competitive perspective leads to a loss of aesthetic appreciation, so the Scylla in this case is the competitive perspective). It is important 
to stress that this is a consequence of thinking of the aesthetic perspective as something we can adopt to the exclusion of the partisan/competitive perspective. So the strict division between the aesthetic way of watching sport and the competitive or partisan way of watching sport creates a dilemma for the purist as described by Mumford (2012a; 2012b). Concentration on the competitive dimension leads to a loss of aesthetic appreciation, and concentration on the aesthetic dimension leads to a failure to appreciate the competitive dimension. Of course, Mumford is perfectly aware that a rigid distinction between the aesthetic way of watching sport and the competitive way of watching sport is inaccurate, but his solution to that problem is to invoke the idea of oscillation and that of a spectrum on which spectators, or their watching of sport on any particular occasion, can be placed depending on a quantitative assessment of the amount of time that they spend watching sport from an aesthetic perspective and the amount of time that they spend watching sport from the competitive perspective. The important thing to stress about this is that $a t$ any given time the spectator can only watch sport in one of the two ways Mumford describes (aesthetic or competitive, or, to be more accurate, purist or partisan those are the only two options available on Mumford's account).

Thus far I've made free use of the notion of 'an aesthetic-shaped hole' without much explanation, so a little more should be said by way of clarification. In addition to the fact that Mumford's idiosyncratic use of 'aesthetic' is such that there seems to be an aesthetic-shaped hole in his account of watching sport because when he talks of the aesthetic he frequently means things that it seems strange to regard as aesthetic, there also seems to be a problem for Mumford's account of the purist in that it suffers from an aesthetic-shaped hole in a different way. Perhaps it would be more accurate to say that in this second way in which the problem arises it is an intermittent aesthetic-shaped hole, in that the hole is apparent when a spectator is said to be watching sport from a competitive perspective. The notion of an aesthetic-shaped hole is similar, although not identical, to that of an 'art-shaped' hole, which was introduced by Fuller (1980). McFee (1992: 294-97) outlines the notion of an art-shaped hole in accounts of art when discussing disputes between aestheticians and sociologists of art. It has been common for many aestheticians to argue that sociologists of art leave out something important in their accounts of art, and many sociologists of art have argued that aestheticians leave out something important in their accounts of art. When what gets left out is something central to art itself, then the account in question is said to have an art-shaped hole. To illustrate this McFee (1992: 295) gives the example of the Caryatids on the Acropolis (also known as 'Doorway of the Maidens'), and Fuller (1980: 236) gives the example of the Parthenon frieze. In both cases the work was made collectively, and in both cases some of the sculpture displays qualities of art while some is merely the work of an artisan, or to put it more accurately some of the artisans were also artists. The craftsmen who worked on the Parthenon frieze all worked under very similar 'ideological, social and cultural conditions' (Fuller, 1980: 236), and the same could be said of the craftsmen who worked on the Caryatids on the Acropolis, so an account given by a sociologist of art that does not extend beyond those ideological, social and cultural conditions leaves an art-shaped hole because it cannot capture the difference between the work of the artisan and that of the artisan who is also an 
artist. Fuller (1980) initially made this point in relation to art criticism of the 1970s, and McFee extends it to work in the sociology of art, and particularly the sociology of dance. McFee (1992: 295) observes that '[a]lthough such writing succeeds in characterizing certain features of the condition of art, it leaves out what makes the object in question art and not something else; it ignores (or leaves out) the aesthetic - the artistic - dimension'.

There are cases in which an aesthetic-shaped hole amounts to an art-shaped hole, such as when the account in question is one of art that omits an aesthetic dimension as part of the account. However, in this case the account in question is one of watching sport, not the appreciation of art, so in this case it is a criticism to say that there is an aesthetic-shaped hole in Mumford's account of the aesthetic appreciation of sport, but it is not a criticism to say that there is an art-shaped hole because sport is not art (Best, 1974; 1978: 99-122; 1985). That sport is not art is something that Mumford accepts, but if someone wished to argue that sport is art, then the obvious response would be to say that if that were the case, then any account like Mumford's in all other respects, but which held that sport is art (if such a thing is possible!) would also contain an art-shaped hole. As I don't think the proposition 'sport is art', understood literally, is meaningful or makes sense, then I will call the particular hole in Mumford's account to which I am referring here (recall, I will also argue that there is a sport-shaped hole in Mumford's account), an 'aesthetic-shaped hole'.

It has been argued thus far that Mumford's purist faces the Scylla of an absence or loss of aesthetic appreciation (an aesthetic-shaped hole) in two senses - because much of what Mumford treats as aesthetic does not seem to be, and because insisting on a distinction between an aesthetic mode of perception and a competitive way of watching sport leads to an intermittent loss of aesthetic appreciation (when sport is watched from a competitive perspective). The purist, as described by Mumford, also faces the Charybdis of failing to appreciate the sport as the sport (a sport-shaped hole) when watching sport from an aesthetic perspective.

\section{Charybdis: the aesthetic perspective}

In this section I will explore the way in which Mumford's account of the aesthetic perspective of the purist as based on a distinct aesthetic mode of perception (and an adverbial theory of perception) leads to the purist failing to appreciate sport qua sport.

Mumford (2012 a: 60) identifies two theories of aesthetic experience. The first, which he calls 'perception theory' is the idea that 'there is a distinctive aesthetic mode of perception that one can adopt, deploy or enter into to gain an aesthetic experience'. He (2013: 11) describes the perception theory as follows:

$\left(T_{\mathrm{P}}\right)$ two persons $a$ and $b$ looking at the same event $\mathrm{E}$, with similar angles on $\mathrm{E}$ and equally reliable perceptual faculties, may nevertheless have distinguishable perceptions of $\mathrm{E}$. 
This is contrasted with what he calls the 'accompaniment theory', which holds that different people perceive the same thing in looking at the same object, but the difference between someone who has an aesthetic perception of the object and someone who does not, is in what accompanies that perception, such as a feeling or thought. The accompaniment theory, therefore, says (Mumford, 2013: 11) that

$\left(T_{A}\right)$ two persons $a$ and $b$ looking at the same event $E$, with similar angles on $E$ and equally reliable perceptual faculties, have indistinguishable perceptions of $E$ but they have different thoughts, beliefs and intentions accompanying those perceptions.

Mumford defends the perception theory, and argues that there is 'a distinctly aesthetic attitude or aesthetic way of seeing' (2012a: 60). He also stresses (2013: 11) that the idea that the partisan and purist watch sport in different ways should be taken 'wholly literally'. However, in evaluating Mumford's position, one need not have, as one's primary concern, the issue of whether there is a distinct aesthetic mode of perception, because even if there is such a thing, in the case of watching sport from an aesthetic perspective the distinction between an aesthetic and a competitive way of watching sport is problematic because it is insufficient to identify a mode of perception independently of that which is perceived. So, in the case of watching sport, competition is a feature of that which is perceived (sport), so to watch sport aesthetically, is, as it were, to watch something that is competitive, aesthetically (or to watch something aesthetically that is fundamentally competitive in nature). This problem can be clarified by looking a little more closely at Mumford's adverbial theory of perception.

An adverbial theory of perception emphasises the way we perceive things, in the sense of different kinds of perceiving, rather than emphasising the thing perceived. This leads to all sorts of peculiar ways of describing adverbial theories of perception. For example, it might be said that, instead of seeing something that is blue, red or square, one sees 'redly', 'bluely', or 'squarely' (Mumford, 2012a: 67) ${ }^{14}$

An obvious objection to adverbial theories of perception is that adverbial translations (translations of sentences that have the form: subject, verb, adjective, noun, into sentences that have the form: subject, verb, adverb) frequently produce nonsense (sentences that are not meaningful sentences in English), and that as a consequence the adverbial theory of perception cannot be of any value. Someone might think, however, that it is possible to overcome what Fish (2010: 36) refers to as, 'the sense of artificiality' in adverbial translations that are a consequence of the fact that many of the adverbs employed in such translations are 'nonstandard' (Fish, 2010: 36). It might, for example, appear that 'the underlying idea is actually quite familiar' (Fish, 2010: 36) if it is pointed out that when we see a tree through a heat haze 'we do not see a blurry tree - the tree does not become blurry - rather we see the tree blurrily' (Fish, 2010: 36). ${ }^{15}$ However, this doesn't bring the clarity that one might at first think because although we can make some sense of seeing something blurrily, as, for example, we might when we have just woken up and our vision is not 
as sharp as usual, or if we are looking through frosted glass, what are we to make of the idea of seeing 'redly', 'bluely' or 'squarely', or worse, of the claim that 'to sense blue is then to sense bluely' (Ducasse, 1942: 232, also see Sellars, 1991: 94-5)? Such talk is nonsense in the strict sense of the word because to say that I see 'bluely' is not a grammatical sentence in English. Such utterances completely ignore the grammar of our language. We do not see bluely, but see things that are blue or see things as being blue. Another way of putting the concern here is to say that many adverbial translations raise the difficulty we find with the notion of sensing bluely, which "misconstrues as basic a "colour" concept which is derived by analogy from colour concepts pertaining to physical objects' (Sellars, 1991: 94). This is important because if the claim that I see a square bluely could be rephrased without loss as the claim that I see the square as being blue, then the adverbial theory of perception would be perfectly intelligible, although perhaps not as useful as its advocates take it to be. But such rephrasing is not possible without altering the claim that advocates of adverbial theories of perception want to make. This is because the adverbial theory is concerned with giving an account that does not posit mental objects, and that regards perception not as the sensing of certain data (sense data), but rather as 'episodes of sensing in particular ways' (Fish, 2010: 36, emphasis in original). Of course, naïve realism does not entail a commitment to the notion of sense data, but nor does it entail a commitment to the notion of sensing bluely and such like. However, if we remove the notion of sense data from consideration, we are still left with the fact that the adverbial view of perception accounts for perceptual episodes not in terms of something perceived (what is perceived), but in terms of a way of perceiving or sensing.

In applying an adverbial theory of perception in giving an explanation of watching sport, Mumford (2012a: 9) claims that 'the partisan and purist see a different game, even when they are present at the same event'. Might it not be less misleading to say that they see the game differently? Certainly, there seems to be some tension between the idea that they see a different game (does that mean different games? Are there two games?), and Mumford's advocacy of an adverbial theory of perception. On such a theory we see bluely, redly, squarely, blurrily etc., so two spectators would see the game differently, but not see a different game. When I see a house blurrily through a heat haze and my friend sees it sharply because viewing it from a different position (not through a heat haze), we don't each see different houses (and, a fortiori, there aren't two houses), but rather we see the same house in different ways (blurrily and sharply).

If we lay aside for now the fact that Mumford's notion of the aesthetic is unusual, and simply consider what it would be for anyone to adopt an aesthetic perspective on a sport, then regarding the aesthetic perspective as something we can adopt to the exclusion of the partisan/competitive perspective is to fall into the problem of not actually watching the sport. This means that not only is there an aestheticshaped hole in Mumford's account of sport spectatorship, but there is also a 'sportshaped hole' (McFee, 2004: 131-2) in that account. 
As noted in $\S 3$, a significant feature of Mumford's account of the partisan and purist ways of watching sport is that it treats aesthetic perception and competitive perception in such a way that aesthetic perception can be adopted to the exclusion of the partisan or competitive perspective. However, if the competition in question in a given case is central to the sport, and we regard the aesthetic way of watching the sport as something that can be adopted independently of a competitive way of watching sport, then that is to confuse a case of not actually watching the sport, but rather something else, such as the movement of bodies or projectiles (a ball, javelin, etc.), for a case of watching the sport.

Mumford (2012 a: 57) does indeed view the purist and partisan ways of watching sport in this way. For example, he says that:

The purist is someone who has this aesthetic mode switched on most of the time, looking at the sporting contest aesthetically. The partisan rarely has it switched on. But there are many possibilities between the fanatic partisan and the out-and-out purist. Many who watch sport will have some combination of partisan and purist tendencies and will switch their aesthetic mode on and off as the occasion takes them.

This view obliged Mumford (2012b) to provide an account of what the movement from one way of watching sport to another consists in, and how it is possible for spectators to move from one way of watching sport to another (partisan to purist or vice versa). He argues that spectators oscillate between the two ways of watching sport and gives an account of how that is possible based on aspect-perception. I have discussed that account elsewhere (see reference omitted for review) and will not rehearse those arguments here (although the idea that oscillation could be the solution to the problem outlined in this paper is considered, and rejected, below). What is important in relation to the focus of this paper is that Mumford treats watching sport from an aesthetic perspective as something that can be done independently of watching sport from a competitive perspective. Indeed, he treats each of the two ways of watching sport as if any one of them can only be employed if the other is not employed. This is shown by the idea of switching aesthetic and competitive perception on and off, and by the idea that spectators oscillate between the two ways of watching sport. By basing his account of oscillation on aspectperception Mumford is committed to such a disjunctive ${ }^{16}$ conception of aesthetic and competitive perception because in examples such as the Neckar cube or the duck-rabbit, one can only see the diagram in one way at a time.

The disjunctive account is problematic however, precisely because the contrast that Mumford wants to draw is between the aesthetic and the competitive. The problem with that is the fact that if the sport someone is watching is fundamentally competitive in nature, then aesthetic perception that excludes competitive perception results not in watching the sport, but something else (movement of bodies, projectiles etc.). This would seem to suggest that there is a sport-shaped hole in Mumford's account of the purist way of watching sport because the exclusion 
of competition in one's watching of fundamentally competitive sports leaves out something that means that what is left is unintelligible qua sport. ${ }^{17}$

Someone might argue that the idea that someone watching sport from an aesthetic perspective is not watching sport is clearly incorrect because they couldn't be watching anything else. After all, if they are watching the movement of bodies, then those bodies are those of athletes and players engaged in sport, and if they are watching the movement of projectiles, then those projectiles are part of the sport. However, the relevant sense of 'watching' here is not simply equivalent to 'looking at'. It is necessary to consider what is seen, and the person watching sport from an aesthetic perspective (on Mumford's account of an aesthetic perspective) does not see the sport, but rather some abstraction such as the movement. So to watch sport in the manner of Mumford's purist is not to watch sport qua sport. ${ }^{18}$

Having raised concerns in $\S 3$ about Mumford's account of watching sport having an aesthetic-shaped hole in two senses, this section has introduced a different concern, namely, that Mumford's exclusive distinction between aesthetic perception and competitive perception, such that they are mutually exclusive at any given time, leads to the problem that someone watching sport from an aesthetic perspective would not, if we accepted Mumford's account, be watching the sport, but rather the movement of bodies, projectiles etc. In that sense Mumford's account of watching sport can be thought of as not only having an aesthetic-shaped hole in two senses, but as also having a sport-shaped hole.

\section{Dissolving the dilemma}

As noted above, Mumford thinks that there is oscillation between the partisan and purist ways of watching sport. Someone might think that the oscillation prevents the dilemma described here arising because it provides a mechanism by which each spectator can view sport in both partisan and purist ways, so no one need be only a 'pure partisan' or a 'pure purist'. However, that is to fail to see that on Mumford's account the spectator is viewing the sporting event from one perspective or the other at any given time. So when the spectator watches sport from an aesthetic perspective, he or she watches it in the purist way Mumford describes, and when the same spectator moves to watching the sport from a competitive perspective, then he or she watches the sport in the partisan way as Mumford describes it. If, as has been argued here, watching sport in the purist way means not watching the sport (qua sport), and watching the sport in the partisan way means that a spectator cannot, at that time, have an aesthetic appreciation of the sport, then the sport spectator as described by Mumford is always subject to one horn of a dilemma, the Scylla of loss of aesthetic appreciation as a result of watching the sport from a partisan perspective, or the Charybdis of not actually watching the sport as a result of watching from a purist perspective. So oscillation does not resolve the problem because on the oscillation theory aesthetic perception and competitive perception (and purist and partisan ways of watching sport) remain entirely distinct, but that is precisely what creates the intermittent aesthetic-shaped hole ${ }^{19}$ the sport-shaped hole, and the Scylla and Charybdis described here. 
So the purist's dilemma only appears if we think of aesthetic appreciation of sport in one particular way, namely as entirely distinct from appreciating the competitive nature of sport, but if we think of aesthetic features of sport (whether beautiful or ugly), and the competitive nature of sport, as aspects of a whole, then the dilemma does not arise.

Equally, and this might amount to the same thing, the dilemma does not arise if we think of aesthetic appreciation in the relevant context as being aesthetic appreciation of $x$. Where ' $x$ ' is quantified as the sport, or some action in the sport, then that necessarily contains competition within it because competition is a feature of the sport (or an aspect of the sport) and the actions within it. Describing aesthetic appreciation as either aspectual, or as aesthetic appreciation of $x$ may just be two different ways of saying the same thing (at least sometimes), but there's no harm in that as long as we recognise that possibility because one of those two descriptions may help one person see how such a way of seeing things helps, but another person may only be helped to see that by the other description.

No doubt some elaboration would help everyone: if we keep a clear view of the fact that the aesthetic appreciation of relevance in relation to watching sport is aesthetic appreciation of sport, then we shouldn't accept any account that sharply

distinguishes aesthetic perception while watching sport from competitive perception because one can't watch competitive sport qua sport without appreciation of the fact that everything that takes place does so in a competitive context. The meaning and evaluation of tactics depends on appreciation of the competitive and rulegoverned context, as do any actions, scoring, fouls etc. Not only that, but our aesthetic appreciation of anything that takes place in the sport, if it is to be aesthetic appreciation of the sport, also requires an appreciation of the competitive context and our aesthetic appreciation will be heightened by appreciation of the competitive context of that which is being appreciated. For example, the overhead kick that scores a goal in the final minute of a match has greater aesthetic value than the same kind of kick performed by a player who is messing around during a break in play while another player is treated for an injury. Importantly, it is not the drama of play in the last minute that lends the overhead kick extra aesthetic significant because 'drama' in the sense in which it is used to describe the closing minutes of a match is not the aesthetic concept of relevance to use of the word in the theatre. What makes the overhead kick that scores a goal in the final minute of the match worthy of greater aesthetic appreciation than the same kind of kick performed during a break in play, and which, therefore, doesn't score a goal, is the creativity evident in attempting such a thing when the stakes are so high, and the skill required to perform it under such pressure. However, that is not to say that such a case has the added aesthetic properties of creativity and the demonstration of skill, but rather to say that in describing what is aesthetically pleasing about the goal (because that is what is being appreciated, not just the kick), the creativity and skill exhibited in those specific circumstances are important aspects to which someone could draw attention in explaining or justifying, or even just in describing, what is aesthetically appealing about the goal. 
What makes this way of seeing things different from Mumford's account is subtle and difficult to see. At every turn the temptation to view aspects of a whole as discrete parts is very strong. It is important to keep the relevant whole in mind at all times, so aesthetic appreciation of sport isn't a disjunctive matter in relation to aesthetic perception and competitive perception (or purist and partisan ways of watching), but rather a matter of adopting an aesthetic perspective on the competitive, so factors of competition are contextually relevant to aesthetic appreciation in the case of watching sport. As aesthetic appreciation in any case has to be aesthetic appreciation of something, and in the case of watching sport the relevant 'something' is the sport or some thing (usually an action) that happens within the sport, such as the goal scored by an overhead kick in the final minute, then there can be no aesthetic perception in relation to watching sport unless it is aesthetic perception of the sport, things that happen within the sport, and aspects of the sport and the things that happen within it. Competition is, as already noted, central to our understanding of actions and events within competitive sports, and our understanding of the sports as a whole, so an account that treats the aesthetic and the competitive in relation to watching sport as entirely distinct, cannot avoid the dilemma outlined here.

This also has implications for the adverbial theory of perception advocated by Mumford. For example, rather than saying we see bluely, we might say that we pay attention to the blueness of the thing (an aspect). Someone might wonder whether the example of seeing a tree blurrily through a heat haze raises a problem for this way of thinking of seeing something blue. However, it is here, rather than in distinguishing between aesthetic perception and competitive perception, that there is a place for disjunction. In other words, either I see the blueness of the thing, or I see the thing as blue (it appears to me as if it is blue) because I'm looking at it in blue light, through blue spectacles or a blue stained glass window etc., or I'm hallucinating. That covers veridical perception, illusion and hallucination, while recognising that each is different. For example, one does not see hallucinations; they are something one has or experiences (see Travis, 2013: 379 and 390 on sense data and 383 hallucinations).

If we return to the six features of Mumford's conception of the aesthetic perspective of the purist that are described in $\S 2$, it is possible to see (again) how those features contribute to the purist's dilemma.

a. Mumford regards certain things as constituting examples of the aesthetic that one might not normally categorise in such a way. This arises from a failure to see that the broadening of the range of terms used to describe artworks does not lead to a broadening of the concept of the aesthetic because when terms such as 'dramatic', 'evocative', 'interesting', 'challenging' and 'moving' are used in relation to works of art, they are used in very particular ways, not just any way. Not appreciating that introduces a constant aesthetic-shaped hole in Mumford's account of sport spectatorship. 
b. Mumford thinks that the drama in sport introduces an aesthetic dimension that renders time limitation of play aesthetic in nature, or of direct relevance to the aesthetic in sport. This is an example of the difficulties that can arise as a result of the misconception in point a. The relevant use of 'drama' in this context is not that in relation to the theatre (which is an aesthetic use of the term), but is, rather, a figurative use that does not entitle us to draw conclusions about the aesthetic.

c. Mumford employs a broad conception of the aesthetic in one sense (that referred to in a above), yet a narrow conception of the aesthetic in another sense because he only considers positive aesthetic value. To only consider positive aesthetic value when thinking about the aesthetic is to do only half a job. The relevant sense of 'aesthetic' surely has to be what Best (1978: 99-100) calls the 'conceptual' use of the term. In other words, we have to attend the dainty as well as the dumpy (Austin, 1979: 183). Although Mumford broadens the conception of the aesthetic in one sense, in doing so he remains solely concerned with positive aesthetic value, but the spectator who goes home disappointed at having seen an ugly game would seem as much of a purist (on the other criteria described by Mumford) as another spectator who goes home from a different match happy at having seen a beautiful game. There is, of course, a narrower sense in which we use the term 'aesthetic' (Best's, 1978: 99-100 'evaluative' use), but that use is not found in all aesthetic appreciation, but only one narrow form of such appreciation.

d. Mumford treats, what he calls, the 'aesthetic mode of perception' (2012a: 60) as entirely distinct from the competitive way of watching sport. It is this sharp distinction that, it has been argued here, creates the purist's dilemma. Employment of the aesthetic mode of perception leads to not watching the sport at all qua sport because appreciation of the competitive nature of the sport is lost, and watching sport with appreciation of the competitive nature of the event leads to a loss of aesthetic appreciation if, as Mumford claims, aesthetic and competitive perception are quite distinct from one another. An alternative way of thinking of sport spectatorship is to see the aesthetic appreciation of sport and the competitive appreciation of sport as drawing different aspects (of the sport as a whole, of a match or sporting event, or of actions in a sporting event) to the fore. Such a view continually preserves the whole, ${ }^{20}$ and so avoids the dilemma faced by the spectator on Mumford's account. Aesthetic appreciation does not lead to a loss of competitive appreciation because the aesthetic appreciation is regarded as appreciation of something that is fundamentally a competitive enterprise in the same way that aesthetic appreciation of a painting has to involve seeing the painting as a painting for it to count as a case of appreciation of the painting. This is precisely the kind of thing that David Best (1978: 102) explains in terms of the means-end distinction. Emphasising the competitive in purposive sports does not lead to loss of the sport in any account, whereas such emphasis in relation to aesthetic sports does fail to appreciate the sport as the sport that it is because an aesthetic dimension is part of what that sport is (a vault is not just a matter of getting over something any old way, and a dive is not just a matter of jumping into water any old way; there is an aesthetic dimension to those concepts. See Best, 1978: 104). 
Someone might think that way of putting things creates a problem for the idea that we can think of watching sport in terms of aspects and avoid the problems of Mumford's account because if Best (1978: 104) is right about what he calls 'the independently specifiable purpose', then one can watch purposive sports by emphasising competition and have no aesthetic appreciation (the loss of aesthetic appreciation that I have referred to as one of the two kinds of aesthetic-shaped hole in Mumford's account), and isn't that to introduce a sharp distinction between competitive and aesthetic perception, which is the very thing that I have diagnosed as the basis of the dilemma for Mumford's purist? It is the diagnosis of the dilemma faced by the purist, but it is only Mumford and those who see sport spectatorship the way he does that face the dilemma because it is only on that account that aesthetic appreciation of sport entails a sharp division between aesthetic and competitive perception. There's no problem with sharply distinguishing between the two in contexts where it doesn't matter, the point is that Mumford sharply distinguished between them in a context (aesthetic appreciation of sport) where it does matter. So to say that we can watch purposive sports as a partisan, and pay no attention to aesthetic matters, is not a commitment to maintaining a universal sharp distinction between the aesthetic and the competitive. That should be obvious because clearly one could appreciate art aesthetically as art without paying any attention to competition. The thing that is being appreciated (the context of the appreciation) determines which conceptual distinctions make sense and which do not. Making a sharp distinction between aesthetic perception and competitive perception in the context of watching competitive sport from an aesthetic point of view leads to incoherence because the thing that is being aesthetically appreciated is fundamentally competitive in nature. An equivalent distinction in the context of watching competitive purposive sports from a competitive perspective does not lead to the same contradiction. So we can watch the competitive from a competitive perspective, that much should seem obvious, but equally we can watch the competitive from an aesthetic perspective, but any satisfactory account of that cannot sharply distinguish between aesthetic perception and competitive perception in such a way that when one employs one it is to the exclusion of the other. It is, however, important to stress that there's nothing wrong with the distinction between the aesthetic and competitive ways of watching sport if it is thought of as aspectual and occasion-sensitive, but Mumford doesn't think of it that way, and thinking of it that way doesn't allow it to be the basis of a theory of sport spectatorship.

e. Mumford thinks spectators oscillate between the partisan and purist ways of watching sport. The need for the oscillation theory arises from the sharp distinction between aesthetic and competitive perception. Thinking of spectatorship in terms of aspects avoids the exclusive distinction in the first place.

f. Mumford advocates a form of adverbial theory of perception that he applies to sport spectatorship. The appeal of an adverbial theory of perception if one wants to give an account of sport spectatorship like Mumford's is that it allows aesthetic perception to be regarded as distinct, but that is precisely what I have argued leads to problems with Mumford's account. Talk of seeing 'bluely' draws attention away 
from what it is that is seen bluely, and it is that shift in attention that leads to problems in the case of watching sport from an aesthetic perspective because, in giving an account, it becomes easy to ignore the fact that the thing one is watching is fundamentally competitive (the rules determine that), so one is watching something competitive aesthetically, not just watching any old thing aesthetically. The, quite correct, idea that one can look at more or less anything aesthetically (Best, 1978: 99) shouldn't lead us to think that therefore when we do look at something in particular aesthetically, it doesn't matter what that thing is. On the contrary, it does matter. An account of looking at a painting aesthetically that has no place for the painting as a painting will not do (as an account of aesthetic appreciation of a painting), and neither will an account of watching competitive sport from an aesthetic perspective that has no place for the sport.

\section{Acknowledgements}

The material in this paper emerged from exploring an element of a paper read to the North American Society for Aesthetics Pacific Division meeting in Pacific Grove, California on 9th April 2015. I'm grateful to Alva Noë, David Davies, James Hamilton, Sean Kelly and Christopher Thi Nguyen for questions and comments on the paper from which this developed, and to Andrew Millie for assistance in relation to some of the references in n. 11. I'm also very grateful to Stephen Mumford for providing me with some of his work and for the interest he has shown in the work I am doing on this and related topics. As always, I'm very grateful to Graham McFee - in this case for inviting me to that conference, reading and commenting on this paper, and for innumerable discussions on the issues considered here.

\section{References}

AUSTIN, J. L. 1979. Philosophical Papers. Third edition. Oxford: Oxford University Press.

BAKER, G. P. 2004. Wittgenstein's Method: Neglected Aspects. Oxford: Blackwell.

BAKER, G. P. and HACKER, P. M. S. 1980. Wittgenstein: Understanding and Meaning An Analytical Commentary on the Philosophical Investigations, Volume One. Oxford: Basil Blackwell.

BAKER, G. P. and HACKER, P. M. S. 1985. Wittgenstein: Rules, Grammar and Necessity - An Analytical Commentary on the Philosophical Investigations, Volume Two. Oxford: Blackwell.

BENNETT, M. R. and HACKER, P. M. S. 2003. Philosophical Foundations of Neuroscience. Oxford: Blackwell.

BEST, D. 1974. The Aesthetic in Sport. British Journal of Aesthetics 14 (3): 197-213.

BEST, D. 1978. Philosophy and Human Movement. London: George Allen \& Unwin. 
BEST, D. 1985. Sport Is Not Art. Journal of the Philosophy of Sport XII: 25-40.

DANTO, A. 2013. What Art Is. New Haven, CT: Yale University Press.

DIXON, N. 2001. The Ethics of Supporting Teams. Journal of Applied Philosophy 18: 149-58.

DUCASSE, C. J. 1942. Moore's Refutation of Idealism. In Schilpp, P. A. (ed.) (1942), The Philosophy of G. E. Moore, vol. I. La Salle, III: Open Court, pp. 225-51.

EATON, M. M. 2004. Art and the Aesthetic. In P. Kivy (ed.) The Blackwell Guide to Aesthetics. Oxford: Blackwell, pp. 63-77.

FAIRHURST, M. T., PRITCHARD, D., OSPINA, D. and DEROY, O. 2015. Bouba-Kiki in the plate: Combining Crossmodal Correspondences to Change Flavour Experience. Flavour 4: 22.

FISH, W. J. 2009. Perception, Hallucination, and Illusion. New York: Oxford University Press.

FISH, W. J. 2010. Philosophy of Perception: A Contemporary Introduction. New York: Routledge.

FULLER, P. 1980. Beyond the Crisis in Art. London: Writers and Readers Publishing Cooperative.

HACKER, P. M. S. 2007. Human Nature: The Categorial Framework. Oxford:

Blackwell.

MARTIN, M. G. F. 2004. The Limits of Self-Awareness. Philosophical Studies. 120 (13): 37-89.

MCFEE, G. 1992. Understanding Dance. London Routledge.

MCFEE, G. 2004. Sport, Rules and Values. London: Routledge.

MCFEE, G. 2011. Artistic Judgement: A Framework for Philosophical Aesthetics. Dordrecht, Netherlands: Springer Verlag.

MCFEE, G. 2015. On Sport and the Philosophy of Sport: A Wittgensteinian approach. Abingdon: Routledge.

MCFEE, G. 2015b. A Not-So-Beautiful Game. Sport, Ethics and Philosophy 9 (2): 16681. 
MUMFORD, S. 2012a. Watching Sport: Aesthetics, ethics and emotion. Abingdon: Routledge.

MUMFORD, S. 2012b. Moderate Partisanship as Oscillation. Sport, Ethics and Philosophy 6 (3): 369-75.

MUMFORD, S. 2012c. Emotions and Aesthetics: an Inevitable Trade-Off? Journal of the Philosophy of Sport 39 (2): 267-79.

MUMFORD, S. 2013. Ways of Watching Sport. Philosophy (supplement) 73: 3-15.

MUMFORD, S. forthcoming. A Beautiful Game? The Aesthetics of Football. In Hughson, J., Maguire, J., Moore, K. and Spaaij, R. (eds) The Routledge Handbook of Football Studies. Abingdon: Routledge.

MUMFORD, S. and LACERDA, T. O. 2010. Genius in Art and Sport: A Contribution to the Investigation of Aesthetics of Sport. Journal of the Philosophy of Sport 37 (2): 182-93.

NAUMANN, F. M. and DUCHAMP, M. 1982. Affectueusement, Marcel: Ten Letters from Marcel Duchamp to Suzanne Duchamp and Jean Crotti. Archives of the American Art Journal 22 (4): 2-19.

SELLARS, W. 1991. Science, Perception and Reality. Atascadero, CA: Ridgeview Publishing Company.

SIBLEY, F. 1959. Aesthetic Concepts. Philosophical Review 68 (4): 421-50.

SIBLEY, F. 2001. Aesthetic Concepts. In Sibley, F. 2001. Approaches to Aesthetics: Collected Papers on Philosophical Aesthetics. Oxford: Oxford University Press, pp. 123.

SPALDING, J. and THOMPSON, G. 2014. Did Marcel Duchamp Steal Elsa's Urinal? The Art Newspaper. Issue 262: November 2014.

SPENCE, C., MICHEL, C. AND SMITH, B. 2014. Airplane Noise and the Taste of Umami. Flavour 3: 2.

SMITH, B. C. 2012a. Complexities of Flavour. S6 Nature. Volume 486. 21 June 2012.

SMITH, B. C. 2012b. The Senses and the Multisensory. In Brockman, J. (ed.) This Will Make You Smarter. New York: Harper Collins, pp. 139-42.

THE JACKDAW. http://www.thejackdaw.co.uk/wp-content/uploads/2015/09/Duchamp-FountainII1.pdf Accessed $6^{\text {th }}$ February 2016. 
TRAVIS, C. 2013. Perception: Essays After Frege. Oxford: Oxford University Press.

WISDOM, J. 1965. Paradox and Discover. Oxford: Basil Blackwell.

WITTGENSTEIN, L. 2001. Philosophical Investigations. Third edition. Translated by G. E. M. Anscombe. Oxford: Wiley-Blackwell.

WITTGENSTEIN, L. 2009. Philosophical Investigations. Fourth revised edition. Edited by P. M. S. Hacker and J. Schulte. Translated by G. E. M. Anscombe, P. M. S. Hacker and J. Schulte. Oxford: Wiley-Blackwell.

\footnotetext{
${ }^{1}$ In that particular paper (2012c), Mumford concentrates on one aspect of the competitive perspective, namely, emotional experience. In this paper I will consider the competitive perspective more widely because doing so identifies additional difficulties that emerge as a consequence of the partisan and purist distinction.

${ }^{2}$ Given Mumford's advocacy of a form of adverbial theory of perception, he would appear to be committed to he idea that these are features of the aesthetic way of watching sport, rather than aesthetic features of sport. That will be discussed further in $\S 4$ below.

${ }^{3}$ There is terminological slippage in directly translating 'purist way of watching sport' as 'aesthetic mode of perception', or even as 'aesthetic way of watching sport', whereas 'partisan way of watching sport' does appear to be more or less synonymous with 'competitive way of watching sport'.

${ }^{4}$ There are growing challenges to the idea that those are distinct. See the literature on crossmodal correspondences and the notion of multisensory experience (and, for that matter, some of the philosophical literature on wine), for example, Fairhurst et al., 2015; Spence et al., 2014; Smith, 2012a and 2012b.

${ }^{5}$ Could it really be the case that Dixon gets the purist wrong? Doesn't he just use the term differently? The term 'purist' may seem more appropriate for the kind of spectator that Mumford describes, but 'purist' isn't a natural kind or some such thing, so it seems strange to accuse Dixon of getting the purist wrong, as if he had mistaken a certain kind of spectator for the purist in the way that someone might mistake a whippet for a greyhound (see Wisdom, 1965: 69).

${ }^{6}$ Clearly this is only one way in which the aesthetic possibilities in these two cases differed.

${ }^{7}$ See Travis (2008) for detailed discussion of the nature and implications of that observation, and McFee (2011) for an investigation of the implications in relation to philosophical aesthetics.

${ }^{8}$ Mumford (2012a: 60) rightly isn't too worried about whether the distinction between the aesthetic and the non-aesthetic can be made sharply. However, he seems to think that in some way 'aesthetic' is equal to 'pleasure', but not all pleasure is aesthetic pleasure, and not everything that is aesthetic is pleasurable (cf. Best's, 1978: 99-100 distinction between the evaluative and conceptual uses of 'aesthetic').

${ }^{9}$ Mumford (2012 a: 22; 49-56) does not accept this view of drama. As I intend to deal with this issue in a separate paper, I will not discuss it in detail here. Mumford (2012 a: 22) also implies that improvisation is a feature that many sports share with some art-forms. However, at least some of the criteria for judging good improvisation in, for example, music, would be aesthetic in nature, and would have to be because of the nature of music, whereas the equivalent criteria for judging good improvisation in purposive sports need not contain a single aesthetic criterion (because of the nature of purposive sports - see Best, 1974 and 1978: 99-122).

${ }^{10}$ One can't help wondering what 'no longer' means here. Wittgenstein's observation (in PI§43) that "For a large class of cases of the employment of the word "meaning" - though not for all - this word can be explained in this way: the meaning of a word is its use in the language', should not, I think, be understood as justification for the view that if some people start using a word differently, such as talking of machines 'thinking', then that changes the meaning of the word. To think that is to fail to appreciate that Wittgenstein did not say that meaning just is use. Apart from the notable
} 
qualifications in PI§43 ('large' is italicised, 'though not for all', and in the Anscombe, Hacker and Schulte translation, which in this case is preferable to the previous translation by Anscombe, 'all' in 'though not for all' has also been italicised), it's important to appreciate that what he actually refers to is not just use, but 'use in the language' (emphasis added). This is important because there is a whole range of what Best (1978: 14) calls 'logical consequences' because of the interrelationships between concepts (also see Hacker, 2007: 7-11; Bennett and Hacker, 2003: 379-86, Baker and Hacker, 1980: 468-9; 1985: 52-5, and Baker, 2004: 55-9). Simply using a word differently does not alter those, so what different uses of that kind do is not alter the meaning of a word in its original sense, but rather introduce a new sense in which it is being used. That in itself is no simple matter. Neither words, nor sentences are the bearers of determinate meaning, but rather something like utterances in a context, but even then our uses of words admit of descriptions and what constitutes an appropriate description depends on one's concern in asking for a description or the nature of one's puzzlement (see Baker, 2004: 55-9). To fail to appreciate that and to think that the same logical implications follow from a new use of a word frequently results in nonsense (in the strict sense saying things that have no sense). So there needn't be any harm in talk of machines thinking and such like as long as no one assumes from the fact that we talk in that way that the machine could doubt its answer is correct, or lack confidence in an assertion it has made. The problem is not just with doubt and lacking confidence, but also with the idea that the machine gives an answer in the sense in which a human being does (or calculates the answer), and with the idea that a machine could assert something (in the sense in which a human being does). Given all of this, it really isn't clear, to me at least, what 'no longer' could possibly mean here.

${ }^{11}$ The attribution of Fountain to Duchamp has been questioned. Spalding and Thompson (2014) make the case for Elsa von Freytag-Loringhoven having made the work as a protest against the United States joining the First World War in 1917. See Naumann and Duchamp (1982: 8), but also, in contradiction to that, Naumann and Duchamp (1982: 18, n. 20), and http://www.thejackdaw.co.uk/wp-content/uploads/2015/09/Duchamp-Fountain-II1.pdf. ${ }^{12}$ Cf. Best (1992: 130 and 1985: 115). Best (1992: 130) stresses that 'I may respond with sadness to a joyful Mozart rondo because it was my dead mother's favourite piece of music. ... [In such a case] understanding of the music may be irrelevant to it [the response]. The feeling just happens to be related to the music by association, since another piece might have been her favourite. Such a response is not part of artistic appreciation; it is not related to features of the music, and notions such as understanding and appropriateness to the character of the music play no part.'

${ }^{13}$ For Duchamp 'readymades' are everyday objects made for some purpose, and not to be art, taken out of their original context by an artist and placed in a context such that 'its useful significance disappeared' (Danto, 2013: 28).

${ }^{14}$ Adverbial theories of perception are largely motivated by providing an account that avoids employing the notion of sense data while avoiding naïve realism - the idea that in good cases of perception, as opposed to cases of illusion or hallucination, one perceives what one does as a result of the nature of the thing perceived because it is the thing perceived and its properties that 'shape the contours of the subject's conscious experience' (Martin, 2004: 64).

${ }^{15}$ It should be stressed that Fish is not an advocate of adverbial theories, but rather of a form of disjunctivism (see Fish, 2009). I have simply employed his example because it helps bring out the contrast to which I want to draw attention.

${ }^{16}$ My use of the term 'disjunctive' here is potentially confusing because Mumford does not subscribe to a disjunctivist account of perception. The relevant disjunction is in the claim that the sport spectator watches sport either in a competitive way or in an aesthetic way, or to be more accurate, either in a partisan way or in a purist way. It is this 'either ... or ...' structure to his account of watching sport that renders that account disjunctive, but his account of perception is adverbial, rather than disjunctivist, in nature.

${ }^{17}$ See McFee (2015: 130-1) and McFee (2015b). McFee (2004: 131) identifies a similar problem in much sociology of sport, where many of the theories 'can tell us everything about sport except what makes it sport - for the terms of the (sociological) discussion apply as well to activities other than sport as they do to sporting activities'.

${ }^{18}$ There are other ways that someone can fail to be concerned with the sport or game. Contrast the way described here with what Best (1978: 74-78, but especially the end of 77 and top of 78) says 
about a causal account of a chess move rather than an account in terms of reasons. Best (1978: 78) accepts that 'there may be causal reactions to chess moves, but they are not normally of any interest to players or spectators. Indeed, if their interests were exclusively causal they could not be said to be interested in the game at all'. This is another way someone can fail to be concerned with the sport or game, but it is different from the problem that faces the purist who views purposive sports from an aesthetic perspective.

${ }^{19}$ Recall, I have also argued that there is another, constant, sense in which there is an aestheticshaped hole in Mumford's account.

${ }^{20}$ What constitutes the relevant whole in any given case depends on one's interest. It could be an action in a match, it could be the match, or it could be the sport as a whole. If one's concern is only with something quite specific, say an action in a match, then the resulting description need not go any further than that, but the important thing to see is that if one's concern changed and it was necessary to have a wider focus, then that would be possible. The relevant whole would simply be the match or the sport. What we are concerned with here is a form of understanding that is useful in relation to complex things. Rather than thinking of them as composed of distinct parts, they are thought of as complex wholes that admit of multiple appropriate descriptions because we can identify countless aspects of the relevant whole. The questions that we ask determine what aspects are of relevance in answering those questions, so for a given concern some aspects are brought to the fore and others pushed into the background for the purpose of assisting with the question at hand, but a different question or concern might require a different emphasis, and so different aspects to be brought to the fore. Any whole is given its relevance by the concern one has in asking the question, so if another question is asked it may shift the focus so that what was the relevant whole (an action in a match) becomes an aspect of a wider whole, such as the match or the sport.

Leon Culbertson, Edge Hill University, Graduate School, Ormskirk, Lancashire, UK, L39 4QP. E-mail: culbertl@edgehill.ac.uk 